\title{
Bottlebrush Copolymer Additives for Immiscible Polymer Blends
}

Hui Zhen Mah, ${ }^{\dagger+}$ Pantea Afzali,${ }^{\dagger}$ Luqing Qi, ${ }^{\S}$ Stacy Pesek, ${ }^{\S}$ Rafael Verduzco, ${ }^{\S} *$ Gila E. $\operatorname{Stein}^{\# *}$

${ }^{\dagger}$ Materials Science and Engineering Program, University of Houston, Houston TX

77204; Department of Chemical and Biomolecular Engineering, University of Houston, Houston TX 77204; ${ }^{\S}$ Department of Chemical and Biomolecular Engineering, Rice University, Houston TX 77006; \# Department of Chemical and Biomolecular Engineering, University of Tennessee, Knoxville TN 37996

\begin{abstract}
Thin films of immiscible polymer blends will undergo phase separation into large domains, but this behavior can be suppressed with additives that accumulate and adhere at the polymer/polymer interface. Herein, we describe the phase behavior of polystyrene/poly(methyl methacrylate) (PS/PMMA) blends with 20 vol\% of a bottlebrush additive, where the bottlebrush has poly(styrene-rmethyl methacrylate) side chains with $61 \mathrm{~mol} \%$ styrene. All blends are cast into films and thermally annealed above the glass transition temperature. The phase-separated structures are measured as a function of time with atomic force microscopy and optical microscopy. We demonstrate that subtle changes in bottlebrush architecture and homopolymer chain lengths can have a large impact on phase behavior, domain coarsening, and domain continuity. The bottlebrush additives are miscible with PS under a broad range of conditions, but are only miscible with PMMA when the bottlebrush backbone is short, or when the PMMA chains are similar in length to the bottlebrush side chains. In all other cases, the limited bottlebrush/PMMA miscibility drives the formation of a bottlebrush-rich interphase that encapsulates the PMMA-rich domains, stabilizing the blend against further coarsening at elevated
\end{abstract}


temperatures. The encapsulated domains are aggregated in short chains or larger networks, depending on the blend composition. Interestingly, the network structures can provide continuity in the minor phases. 


\section{INTRODUCTION}

Polymer blends can exhibit superior bulk properties than the pure constituents, such as enhanced toughness and impact strength ${ }^{1,2}$. However, most polymer blends will undergo macroscale phase separation ${ }^{2,3}$ to generate large and ill-defined domains with weak adhesion at the polymer/polymer phase boundary. Consequently, a phase-separated material will exhibit poor mechanical properties. Surface-active additives such as block polymers ${ }^{4-9}$, random copolymers $^{8,10,11}$, and polymer-grafted nanoparticles ${ }^{12-16}$ will accumulate and adhere at the polymer/polymer interface, thereby dispersing the immiscible polymers into small domains and stabilizing the structures against further coarsening and coalescence. A variety of microstructures can be achieved with proper blend formulation and additive design, including discrete domains or continuous networks with sub-micron length scales ${ }^{17}$.

Many polymeric compatiblizers are synthesized from monomers that match the blend constituents. If the blend is comprised of immiscible A and B homopolymers, then copolymers with random or blocky AB sequences can be effective compatibilizers. The copolymer architecture is an important parameter that impacts the surface activity, interfacial strength, and kinetics of structure formation. Long copolymers can form multiple loops between the two phases, which is advantageous for adhesion at the phase boundary ${ }^{11,18}$, and they produce a larger reduction in the interfacial tension ${ }^{8}$. Increasing the "blockiness" in a copolymer favors surfactant-like behavior, meaning the additive forms a monolayer at the polymer/polymer interface, while a more random monomer sequence can drive the formation of an interfacial wetting layer $^{10,18}$. Finally, molecular geometry also impacts the interfacial tension: for example, long comb copolymers with many grafted side-chains are more effective compatibilizers than short linear block polymers ${ }^{8}$. 
Nanoparticle compatibilizers are often coated with polymer brushes that match the

25 chemistry of the parent homopolymers ${ }^{12}$. The objective of these coatings is to generate particles

that are evenly wet by the blend constituents, thereby favoring their placement at the A/B interface $^{12,14,19}$. The brushes could be mixtures of A and B homopolymer chains ${ }^{13,16}$, AB random copolymer chains $^{20}$, or even pure homopolymer chains ${ }^{15,21}$. The architecture of the brush, i.e., areal chain density and chain length, will also impact interfacial activity. Nanoparticle compatibilizers can produce similar blend microstructures as polymeric surfactants, including both discrete domains and co-continuous phases ${ }^{13,15}$. However, the adsorption of nanoparticle compatibilizers at an A/B interface is strong and nearly irreversible, so the microstructure can withstand prolonged high-temperature annealing ${ }^{13,15}$ and shear flow ${ }^{16}$.

In this study, we report the design of bottlebrush copolymer compatibilizers for immiscible polymer blends. Bottlebrush polymers are architecturally similar to comb polymers, accumulate at the interfaces of linear polylactic acid films ${ }^{25}$, and low concentrations of bottlebrush polystyrene will spontaneously accumulate at the interfaces of linear polystyrene

42 films ${ }^{26}$. The latter study proposed that bottlebrush polymer additives are more closely related to polymer-grafted nanoparticles than comb polymers: the highly-branched architecture leads to 44 poor miscibility with long linear polymers ${ }^{26,27}$, and there is a strong entropic drive for placement 
47 Therefore, we expect that bottlebrush additives could rapidly de-mix from a blend, localize at the

$48 \mathrm{~A} / \mathrm{B}$ interface, and inhibit coarsening of the microstructures. The objective of this work is to

49 identify the architectural parameters that enable such behavior.

EXPERIMENTAL METHODS

51 Materials. All reagents and solvents were purchased from commercially available sources and

52 used as received unless noted. 2,2'-Azobis(2-methylpropionitrile) (AIBN) was purified by

53 recrystallizing in methanol. Inhibitors were removed from styrene and methyl methacrylate

54 monomers using an aluminum oxide column. Dichloromethane was dried with molecular sieves

55 (4 Å). Exo-7-oxabicyclo [2.2.1] hept-5-ene-2,3-dicarboxylic anhydride, norbornene-

56 functionalized chain transfer agent (NB-CTA) and modified Grubbs' catalyst

$57 \quad\left(\mathrm{H}_{2} \mathrm{IMes}\right)(\mathrm{pyr})_{2}(\mathrm{Cl})_{2} \mathrm{RuCHPh}$ were synthesized using previously reported methods ${ }^{29}$.

58 Linear Homopolymers. Linear polystyrenes ( $\mathrm{PS}_{1}$ and $\mathrm{PS}_{2}$ ) and poly (methyl methacrylates)

$59 \mathrm{PMMA}_{1}$ were purchased from Polymer Source. PMMA 2 was synthesized via reversible addition-

60 fragmentation chain-transfer (RAFT) polymerization. $\mathrm{PMMA}_{3}$ was purchased from Agilent 61 Technologies.

\begin{tabular}{|l|l|l|l|}
\hline Polymer & $M_{n}, \mathrm{~kg} / \mathrm{mol}$ & $N$ & $D$ \\
\hline PS $_{1}$ & 14.8 & 142 & 1.03 \\
\hline PS $_{2}$ & 15.9 & 153 & 1.01 \\
\hline PMMA $_{1}$ & 15.7 & 157 & 1.25 \\
\hline PMMA $_{2}$ & 13.3 & 133 & 1.20 \\
\hline PMMA $_{3}$ & 16.7 & 167 & 1.04 \\
\hline
\end{tabular}


62 Table 1: Homopolymer Characterization. $M_{n}$ is number-average molecular weight, $N$ is degree of

63 polymerization and $Ð$ is dispersity.

64 Random Copolymer Macromonomer. Linear poly (styrene-r-methyl methacrylate) macromonomers, NB-P(S-r-MMA)-CTA, were synthesized via reversible addition-

66 fragmentation chain-transfer (RAFT) polymerization. S (1.75g, 16.9mmol), MMA (1.7g,

$6717.0 \mathrm{mmol})$ NB-CTA (117mg, $0.211 \mathrm{mmol})$ and AIBN (3.53mg, 0.0215mmol) were added into a

$6825 \mathrm{~mL}$ round bottom flask. The solution was purged with nitrogen gas for 30 minutes. The 69 polymerization was initiated by placing the flask in an oil bath at $65^{\circ} \mathrm{C}$. After 6 hours, the flask 70 was removed and quenched by immersing in an ice bath. The polymer was then obtained by 71 precipitating in methanol at $4^{\circ} \mathrm{C}$ and dried under vacuum.

72 Bottlebrush Random Copolymer (RCBB). Bottlebrush with random copolymer poly (styrene73 r-methyl methacrylate) side-chains, hereafter referred to as $\mathrm{RC}$, was prepared by ring-opening 74 metathesis (ROMP) polymerization using the modified Grubbs' catalyst. NB-P(S-r-MMA)-CTA 75 macromonomers were added to a dry, $25 \mathrm{~mL}$ round-bottom flask with a stir bar. The flask was 76 then degassed with three pump-purge cycles, and the desired amount of degassed, anhydrous 77 dichloromethane (DCM) was added for a total macromonomer concentration of 0.02-0.05 M. In 78 a separate flask, (H2IMes) (pyr) $)_{2}(\mathrm{Cl})_{2} \mathrm{RuCHPh}$ was dissolved in degassed, anhydrous DCM. The 79 catalyst solution was then transferred to the macromonomer-containing reaction flask using a 80 cannula, which initiates the polymerization. The reaction flask was stirred at room temperature 81 for at least 1 hour, and the reaction was then quenched with butyl vinyl ether. The product was 82 collected by precipitation in methanol at $4^{\circ} \mathrm{C}$ and dried under vacuum at room temperature. 


\begin{tabular}{|l|l|l|l|l|l|}
\hline$T g$ & $f_{\mathrm{PS}}$ & $N_{\mathrm{sc}}$ & $\bigoplus_{\mathrm{sc}}$ & $N_{\mathrm{b}}$ & $\bigoplus_{\mathrm{b}}$ \\
\hline $\mathrm{RCBB}_{1}$ & 0.61 & 59 & 1.22 & 115 & 2.2 \\
\hline $\mathrm{RCBB}_{2}$ & 0.61 & 59 & 1.20 & 52 & 1.4 \\
\hline $\mathrm{RC}$ & 0.61 & 59 & 1.22 & --- & --- \\
\hline
\end{tabular}

Table 2: Properties of RC and RCBB additives. RC/RCBB side chains have composition $f_{\mathrm{PS}}$ (mole fraction styrene), degree of polymerization $N_{\text {sc }}$, and dispersity $\bigoplus_{\text {sc. }}$ Backbone degree of polymerization and dispersity are $N_{\mathrm{b}}$ and $\bigoplus_{\mathrm{b}}$, respectively.

\section{Instrumentation}

Gel Permeation Chromatography (GPC). GPC was performed using a system with an Agilent 1200 module containing three PSS SDV columns in series (100, 1000 and $10000 \AA$ pore sizes), an Agilent variable wavelength UV/vis detector, a Wyatt Technology HELEOS II multiangle laser light scattering (MALLS) detector $(\lambda=658 \mathrm{~nm})$, and a Wyatt Technology Optilab rEX RI detector. This system enables size exclusion chromatography (SEC) with simultaneous refractive index (SEC-RI), UV/vis (SEC-UV/vis) and MALLS detection. The mobile phase used in this system was $\mathrm{THF}$ at $40^{\circ} \mathrm{C}$ with a flow rate of $1 \mathrm{~mL} / \mathrm{min}$. Molecular weights and dispersities of linear PS were obtained by conventional calibration with a polystyrene column. In the case of PMMA-containing bottlebrush and linear polymers, the molecular weights were calculated from the $\mathrm{dn} / \mathrm{dc}$ values measured using a $100 \%$ mass recovery method assumption. A detailed explanation of this method is included in Supporting Information.

Nuclear Magnetic Resonance Spectroscopy (NMR). Using a 400 MHz Bruker multinuclear spectrometer, the hydrogen NMR $\left({ }^{1} \mathrm{H}\right.$ NMR) spectra was obtained in $\mathrm{CDCl}_{3}$ with 
103 tetramethylsilane as an internal standard. Samples with a concentration of $10 \mathrm{mg} / \mathrm{mL}$ were placed 104 in $5 \mathrm{~mm}$ o.d. tubes.

105 Atomic Force Microscopy (AFM). AFM was performed using a Veeco Dimension 3000 106 Atomic Force Microscope. The topography and phase contrast were measured through tapping 107 mode. The probes were silicon with an aluminum reflex coating, spring constant of 108 approximately $40 \mathrm{~N} / \mathrm{m}$, and resonance frequency of $300 \mathrm{kHz}$. The parameters used for image 109 acquisition were $1.0 \mathrm{~Hz}$ scan frequency, $10 \mu \mathrm{m}$ x $10 \mu \mathrm{m}$ and $20 \mu \mathrm{m}$ x $20 \mu \mathrm{m}$ scan sizes, and 512 $110 \mathrm{x} 512$ image resolution. Raw AFM data were processed using the Nanoscope 6.14R1 software 111 from Veeco Instruments. Zeroth-order flattening was used to process both height and phase 112 images. This eliminates any $\mathrm{Z}$ offsets formed between scan lines by subtracting each point in the 113 scan line with an average $\mathrm{Z}$ value $(\mathrm{Z}=$ phase or height $)$.

114 Contact Angle (CA) Goniometry. The contact angle of DI water on functionalized substrates 115 was measured using a Dataphysics OCA 15EC goniometer. The contact angle measurements 116 were recorded for 60 seconds at 6.25 frames per second from three different areas of the sample.

117 The measurements were then plotted out against a logarithmic time scale, and the equilibrium 118 angle was determined from the observed plateau.

119 Sample Preparation.

120 Substrates. Substrates used for all studies were (100)-oriented p-type silicon wafers. Each 121 substrate was rinsed in deionized water to remove dust particles from the surface and dried under 122 a nitrogen stream. Organic contamination was removed with an ultraviolet-ozone cleaner, and a 123 clean oxidized surface was confirmed with measurements of water contact angle $\left(<5^{\circ}\right)$. A 124 hydroxyl-terminated poly(styrene-r-methyl methacrylate) random copolymer was grafted to the 
125 clean silicon surface to form a "neutral" brush layer, which is intended to screen preferential 126 interactions between PMMA and the underlying substrate. ${ }^{30,31}$ The random copolymer was 127 purchased from Polymer Source, and has an $M_{n}=6.8 \mathrm{~kg} / \mathrm{mol}, \mathrm{D}=1.25$, and $62 \mathrm{~mol} \%$ styrene 128 content. The brush was prepared following the protocol described elsewhere ${ }^{32}$. The measured 129 water contact angle of the brush layer ranges from $77-83^{\circ}$.

130 Polymer Blend Films. The PS/PMMA blend compositions were varied from 45 vol\% to 55 131 vol\% with an uncertainty of \pm 1 vol\%. Additives (linear random copolymer or bottlebrush 132 random copolymer) were included in some films at concentrations of $20 \mathrm{wt} \%$ relative to the total 133 amount of PS and PMMA. The polymers (PS, PMMA, additives) were dissolved in toluene at a 134 concentration of 3.4-3.6 wt\% and the solution was filtered with two $0.2 \mu \mathrm{m}$ Teflon mesh. Films 135 with thicknesses of $150 \mathrm{~nm}( \pm 10 \mathrm{~nm})$ were prepared by spin-casting on the brushed silicon 136 wafers. Thicknesses of as-cast films were measured with a J.A. Woollam M-2000 spectroscopic 137 ellipsometer. The ellipsometry parameters $\Delta$ and $\psi$ were modeled by describing the polymer's 138 optical properties with the Cauchy dispersion relation, $\mathrm{n}(\lambda)=\mathrm{A}+\mathrm{B} / \lambda^{2}$, where $\lambda$ is the incident 139 wavelength $(\mathrm{nm})$. The optical properties of silicon and native oxide are part of a built-in 140 database. A, B, and film thickness are adjustable parameters for regression analysis. Typical 141 values for A and B are 1.5 and 0.01 , respectively. All films were annealed on a hotplate in air 142 (unless stated otherwise) at $150{ }^{\circ} \mathrm{C}$ for times ranging from 0 to $85 \mathrm{~min}$.

143 Selective Removal of PS Domains. PS domains were selectively dissolved from the blend films 144 using cyclohexane. Samples were soaked in cyclohexane for at least 60 seconds and were dried 145 using nitrogen gas.

146 Image and Domain Size Analysis. The sizes and areas of microstructures were determined by 147 analysis of AFM phase images using ImageJ software. First, the phase images were converted 
148 into an 8-bit grayscale image. Second, the image contrast, brightness, and threshold were 149 adjusted to enhance the areas of interest for analysis. Third, image noise was removed by 150 correcting odd pixels with the median of surrounding pixels using the "remove outliers" 151 function. Last, the perimeter $p$ and area $A$ of the domains were calculated with the built-in 152 particle analysis function. The domain sizes of the microstructures were then calculated by 153 Equation 13:

$$
\text { Domain Size }=\pi A / P
$$

155 Where $\mathrm{A}$ is the area of the microstructure and $\mathrm{P}$ is the perimeter of the microstructure.

156 Histograms of the distribution of the minority domains were based on the area fraction of the 157 minority domains within each range. The area fractions of the minority domains were calculated 158 by dividing the sum of areas of minority domains in each range by the overall areas of the 159 minority domains.

\section{RESULTS AND DISCUSSION}

We investigate the effects of bottlebrush copolymer additives on the phase behavior of

162 PS/PMMA blends. Table 1 summarizes the properties of the linear PS and PMMA samples. The 163 bottlebrush copolymer (RCBB) additives are synthesized by a "grafting through" reaction based 164 on ring-opening metathesis polymerization (ROMP) of poly (styrene-r-methyl methacrylate) 165 (PS-r-PMMA) macromonomers with norbornene end groups. This scheme generates one PS-r166 PMMA side-chain per backbone norbornene. To test for enthalpic effects, we also examined 167 PS/PMMA blends with PS-r-PMMA macromonomers (RC), i.e., a linear additive with the same 168 length as bottlebrush side chains. The characteristics of all copolymer additives are summarized 169 in Table 2. 
All PS/PMMA blend films were prepared with no additive, 12 vol\% and 20 vol\% of

$171 \mathrm{RCBB}_{1}$, or 20 vol\% of RC. The use of films rather than bulk samples allows us to distinguish

172 between PS, PMMA, and RC/RCBB additives through AFM phase imaging ${ }^{25-27}$. PMMA-rich

173 domains are the "brightest" phase in the measurements, PS-rich is the darkest, and RC-

174 rich/RCBB-rich structures generate intermediate contrast. A commonly encountered

175 complication with thin film blends is vertical stratification of constituents due to surface and 176 substrate attraction $^{33}$. PS and PMMA have very similar surface tensions ${ }^{34}$, but PMMA is strongly

177 adsorbed at a silicon substrate. Therefore, silicon substrates were coated with a "neutral" PS-r-

178 PMMA brush to suppress adsorption of PMMA at the native oxide ${ }^{31}$.

All as-cast films exhibited bumps at the free surface that are approximately $0.5 \mu \mathrm{m}$ in diameter and $80 \mathrm{~nm}$ tall (Figure $\mathrm{S} 1$ ). These protrusions are assigned to a PMMA-rich phase

181 based on the imaging contrast. Such structures are routinely observed in thin film PS/PMMA 182 blends when PS is more soluble in the casting solvent than PMMA ${ }^{31,35}$, and are explained by the 183 relative drying rates of each phase ${ }^{35}$ : During spin-casting, PMMA is more rapidly depleted of 184 toluene and will "harden" while PS remains swollen. As the PS phase dries, it collapses around 185 the PMMA-rich domains and generates the high-curvature topography. This initial state is highly 186 non-equilibrium, so subsequent annealing above the glass transition (of PS, PMMA, and 187 additives) drives changes in film topography and activates further phase separation. The 188 microstructures that evolve depend on the blend composition and the type of additive.

189 We checked for through-film uniformity of annealed microstructures by washing away 190 PS in cyclohexane (Figure S2) and found that AFM measurements of the surface are 191 representative of the through-film morphology when the molecular weights of PS and PMMA 192 homopolymers are low (PS $\left.1 / \mathrm{PMMA}_{1}, \mathrm{PS}_{1} / \mathrm{PMMA}_{2}\right)$. As discussed in the Supporting 

domains are larger near the substrate compared with the surface.
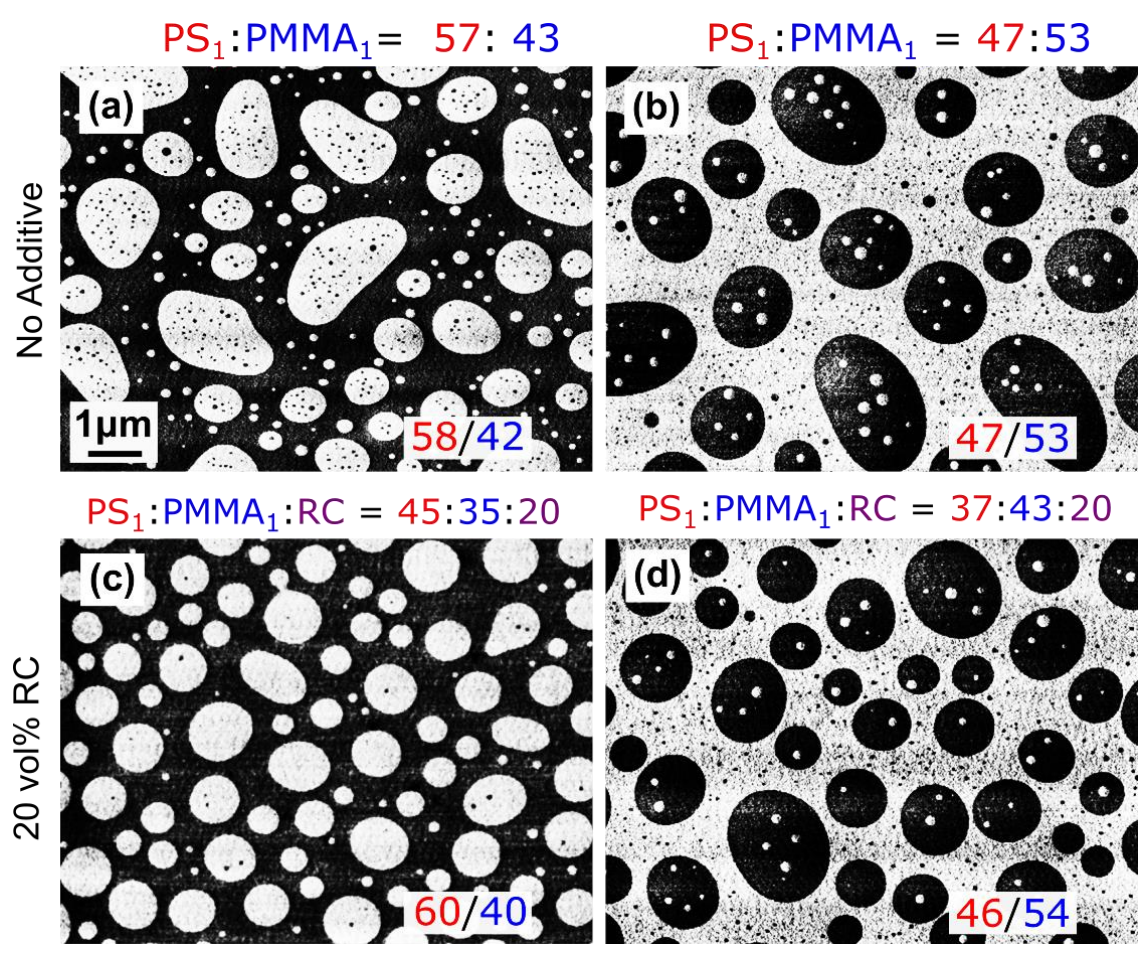

Figure 1. AFM phase images of $\mathrm{PS}_{1} / \mathrm{PMMA}_{1}$ blend microstructures annealed for $85 \mathrm{~min}$, with $(a, b)$ no additive; $(c, d)$ RC additive. The proportion of $\mathrm{PS}_{1}: \mathrm{PMMA}_{1}$ is constant in each column (left: 57:43, right: 47:53). Relative volumes of blend constituents are noted above each micrograph, and the measured relative areas of $\alpha: \beta$ or $\alpha: \beta: \gamma$ phases are marked in the bottomright of each image. The contrast of $\alpha, \beta$, and $\gamma$ phases are dark, bright, and intermediate, respectively.

Figures $1 \mathrm{a}$ and $1 \mathrm{~b}$ report the microstructure of $\mathrm{PS}_{1} / \mathrm{PMMA}_{1}$ blends having PS volume fractions of $\Phi_{\mathrm{PS}}=0.57$ and 0.47 . Using Flory-Huggins theory ${ }^{2,3,36}$, we estimate that the majority phase will switch from PS-rich to PMMA-rich at $\Phi_{\mathrm{PS}} \approx 0.5$ (see Supporting Information). After 85 min of annealing, the outcomes of $\mathrm{PS}_{1} / \mathrm{PMMA}_{1}$ are as-expected: blends with $\Phi_{\mathrm{PS}}>0.5$ phaseseparate into a PS-rich matrix with PMMA-rich minority domains, while blends with $\Phi_{\mathrm{PS}}<0.5$ exhibit the inverse structure. We then consider the effects of RC linear additive on $\mathrm{PS}_{1} / \mathrm{PMMA}_{1}$ blends. The proportion of $\mathrm{PS}_{1}: \mathrm{PMMA}_{1}$ remains the same, i.e., 57:43 and 47:53 vol:vol, but the 
212 the RC additive reduces the size of the of minority domains and increases their circularity, but

213 the microstructures are otherwise very similar to blends with no additive. Figure S6 reports the

214 size distribution of minority domains for each proportion of $\mathrm{PS}_{1}: \mathrm{PMMA}_{1}$ with and without RC

215 additive.
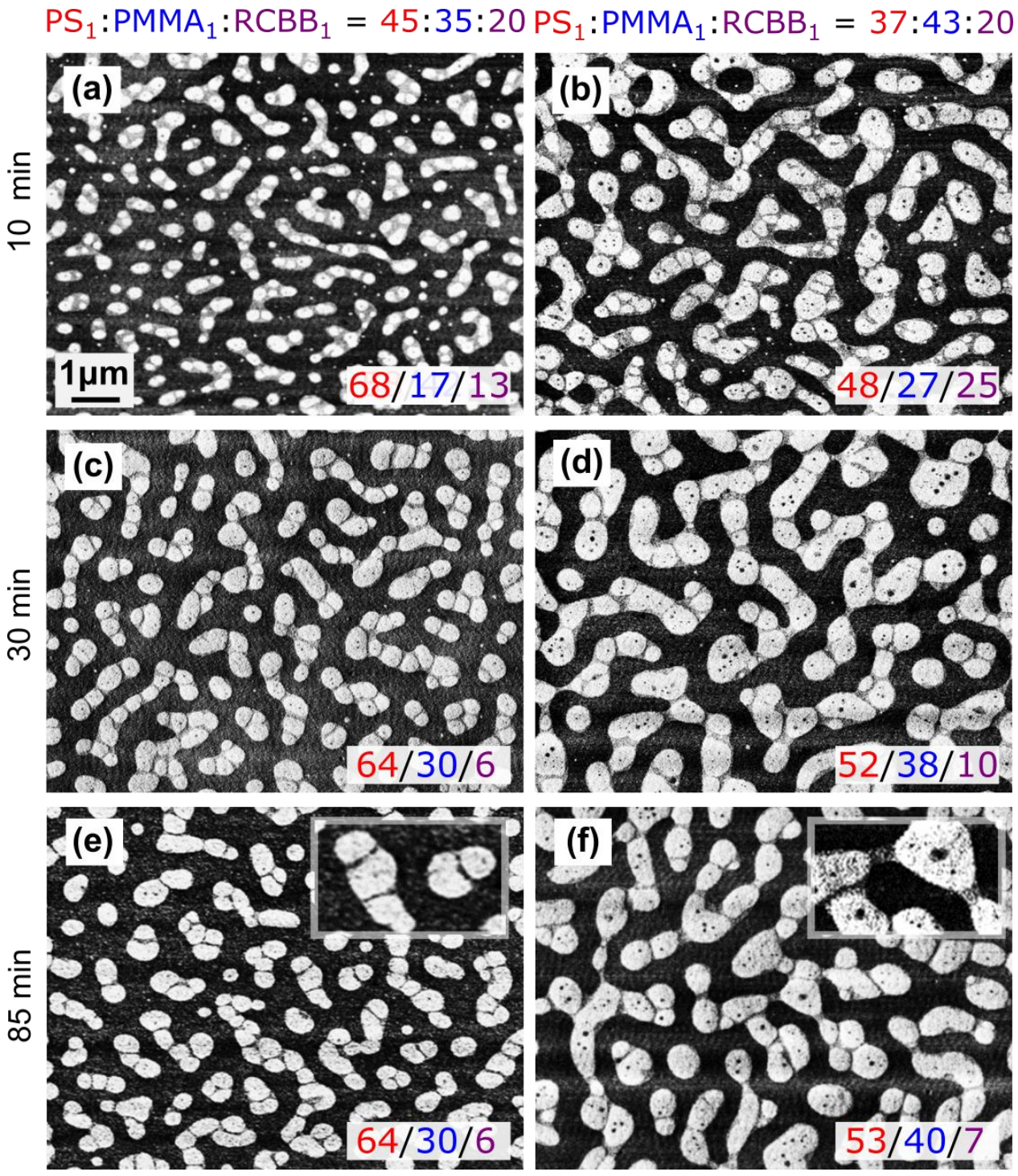

Figure 2. AFM phase images of $\mathrm{PS}_{1} / \mathrm{PMMA}_{1}$ blends with $20 \mathrm{vol} \%$ of $\mathrm{RCBB}$ additive. $(\mathrm{a}, \mathrm{b}) 10$ $\mathrm{min}$; (c,d) $30 \mathrm{~min}$; and (e,f) $85 \mathrm{~min}$, inset at twice the magnification. Relative volume of $\mathrm{PS}_{1} / \mathrm{PMMA}_{1}$ blend constituents is fixed in each column (left: 57:43, right: 46:54), and relative volumes of $\alpha: \beta$ or $\alpha: \beta: \gamma$ phases are marked in the bottom-right of each image. The contrast of $\alpha$,

$221 \beta$, and $\gamma$ phases are dark, bright, and intermediate, respectively. 
224 are reported in Figure 2 as a function of annealing time; $2 \mathrm{e}$ and $2 \mathrm{f}$ show data for 85 min, which is 225 the same annealing time that is shown in Figure 1. There are two clear changes in the phase226 separated structure: First, both blend compositions show a PS-rich majority phase, which 227 demonstrates that $\mathrm{RCBB}_{1}$ additive is not evenly distributed between $\mathrm{PS}_{1}$ and $\mathrm{PMMA}_{1}$. Second, 228 the $\mathrm{RCBB}_{1}$ additive drives the formation of a three-phase system. The microstructure in these 229 cases resembles chains of small, circular PMMA-rich domains encapsulated by a RCBB-rich 230 interphase.

231 The composition of each phase was estimated through image analysis and mass balances. 232 First, the areas of PS-rich $(\alpha)$, PMMA-rich $(\beta)$, and bottlebrush-rich $(\gamma)$ phases were calculated 233 from the AFM phase images. These microstructures are uniform with depth (Figure S2), so the 234 area fraction of each phase at the surface is equal to the bulk volume fraction $(V)$. The volume 235 fractions of each phase are reported at the bottom-right of each micrograph in Figure 1. Second, 236 the total amount of PS, PMMA, and additive in each blend are known, so the composition of 237 each phase can be determined from a mass balance ${ }^{31}$. The general form of this mass balance for a 238 two-phase system is

239 (2) $\Phi_{P X}=\varphi_{P X}^{\alpha} V^{\alpha}+\varphi_{P X}^{\beta} V^{\beta}$,

240 and for a three-phase system is

(3) $\Phi_{P X}=\varphi_{P X}^{\alpha} V^{\alpha}+\varphi_{P X}^{\beta} V^{\beta}+\varphi_{P X}^{\gamma} V^{\gamma}$. 
242 In equations (2) and (3), the symbol "PX" designates the type of polymer, such as $\mathrm{PS}_{1}, \mathrm{PMMA}_{1}$,

$243 \mathrm{RC}, \mathrm{RCBB}_{1}$, etc. The parameters $\varphi_{P X}^{i}$ are the volume fractions of polymer " $P X$ " in phase " $i$ " and

244 are determined by solving the system of linear equations.

For the binary $\mathrm{PS}_{1} / \mathrm{PMMA}_{1}$ blends, we estimate $\varphi_{P S}^{\alpha}=0.95$ and $\varphi_{P S}^{\beta}=0.04$. These

246 values are consistent with predictions from Flory-Huggins theory (Supporting Information),

247 which offers validation for the mass balance approach and suggests that the blend compositions

248 are equilibrated. The compositions of each phase in the ternary $\mathrm{PS}_{1} / \mathrm{PMMA}_{1} / \mathrm{RC}$ blend are

249 summarized in Table 3 . These data demonstrate that $\mathrm{RC}$ additive with $f_{\mathrm{PS}}=0.61$ is miscible with

250 both homopolymers up to at least $20 \%$ by volume. The estimated compositions of each phase in

251 the ternary $\mathrm{PS}_{1} / \mathrm{PMMA}_{1} / \mathrm{RCBB}_{1}$ blends are summarized in Table 4. The estimated compositions

252 of the PMMA-rich and bottlebrush-rich phases are reported with large uncertainties, as there are

253 degeneracies when fitting a large number of parameters to a limited data set. However, we

254 determined that $\mathrm{RCBB}_{1}$ is partially miscible with $\mathrm{PS}_{1}$, but limited miscibility with $\mathrm{PMMA}_{1}$

255 drives the formation of a bottlebrush-rich $\gamma$ phase.

The limited miscibility between $\mathrm{RCBB}_{1}$ additive and $\mathrm{PMMA}_{1}$ could arise from enthalpic

incompatibility between these constituents, entropic factors due to the highly branched

258 bottlebrush architecture, or both effects. With regards to enthalpic interactions, the linear RC

259 additive has the same styrene composition as $\mathrm{RCBB}_{1}\left(f_{\mathrm{PS}}=0.61\right)$ and is equally soluble in both

$260 \mathrm{PS}_{1}$ and $\mathrm{PMMA}_{1}$ up to 20 vol\% (Table 3, Figure 1). It is important to note that the RC additive is

261 the same molecular weight as the $\mathrm{RCBB}_{1}$ side chains, meaning the overall size of the bottlebrush

262 additive is much larger than the linear additive, so this control experiment does not cleanly

263 separate the role of enthalpic interactions from the entropic effects of architecture and molecular

264 weight. Furthermore, the bottlebrush/linear interface is characterized by a high density of side- 
chain end groups (dodecyl, from the RAFT chain transfer agent), so the unusual architecture

266 could magnify the effects of end-group compatibility with each homopolymer. ${ }^{37}$ Therefore, we

267 examine the roles of enthalpic interactions by synthesizing a series of bottlebrush random

268 copolymers with short backbones, and examine their miscibility in PS/PMMA blends. The

269 outcomes are reported in the Supplemental Information (Figure S14). These data suggest that

270 dodecyl-terminated bottlebrushes with $f_{\mathrm{PS}} \sim 0.5$ have near-equal solubility in PS and PMMA.

271 While this result may seem intuitive, the miscibility of linear poly(styrene-r-methyl

272 methacrylate) in PMMA and PS has been examined by others, ${ }^{38,39}$ and these studies demonstrate

273 that S-rich poly(styrene-r-methyl methacrylate) copolymers are more soluble in PMMA than PS.

Entropic factors can strongly influence the miscibility of architecturally-complex

polymer blends. Prior studies have shown that the miscibility of bottlebrush and linear polymer

architectures is partly controlled by backbone and side chain conformational entropy. In the

277 absence of enthalpic interactions, short linear chains can swell a long bottlebrush additive and

278 promote backbone extension, while long linear chains drive bottlebrush contraction to an ideal

279 coil. $^{27}$ It has also been proposed that short linear chains can penetrate and "wet" the bottlebrush

280 side-chains, ${ }^{26}$ similar to the wetting of linear polymers at "brushy" surfaces, ${ }^{40}$ which enables

281 their dispersion in the linear melt. In the present system, the PMMA 1 chains are longer than $\mathrm{PS}_{1}$,

282 and PMMA is slightly stiffer than $\mathrm{PS}^{36}$, so $\mathrm{PMMA}_{1}$ is a poorer "solvent" for the highly-

283 branched $\mathrm{RCBB}$ additive than $\mathrm{PS}_{1}$. The various roles of bottlebrush architecture on blend

284 compatibility are further elaborated in later sections of this manuscript.

285

286 Table 3: Compositions of PS-rich $(\alpha)$ and PMMA-rich ( $\beta$ ) phases in PS1:PMMA1:RC

287 blends, calculated from analysis of $V^{\alpha}$ and $V^{\beta}$ in 45:35:20 and 37:43:20 blends. 85 min 288 anneal. 


\begin{tabular}{|c|c|c|}
\hline $\mathrm{PX}$ & $\varphi_{P X}^{\alpha}$ & $\varphi_{P X}^{\beta}$ \\
\hline $\mathrm{PS}_{1}$ & 0.7 & 0.1 \\
\hline $\mathrm{PMMA}_{1}$ & 0.1 & 0.7 \\
\hline $\mathrm{RC}$ & 0.2 & 0.2 \\
\hline
\end{tabular}

Table 4: Compositions of PS-rich ( $\alpha$ ), PMMA-rich $(\beta)$, and bottlebrush-rich $(\gamma)$ phases in PS1:PMMA1:RCBB 1 blends, calculated from analysis of $V^{\alpha}, V^{\beta}$, and $V^{\gamma}$ in 45:35:20 and 37:43:20 blends. 85 min annealed.

\begin{tabular}{|c|c|c|c|}
\hline $\mathrm{PX}$ & $\varphi_{P X}^{\alpha}$ & $\varphi_{P X}^{\beta}$ & $\varphi_{P X}^{\gamma}$ \\
\hline $\mathrm{PS}_{1}$ & 0.7 & $0.01-0.02$ & $0.05-0$ \\
\hline $\mathrm{PMMA}_{1}$ & 0.1 & $0.84-0.92$ & $0.43-0$ \\
\hline $\mathrm{RCBB}_{1}$ & 0.2 & $0.15-0.06$ & $0.52-1$ \\
\hline
\end{tabular}

296 for two blend compositions, with the corresponding OM data in Figure S7. The microstructure 297 quickly develops, but there is exchange of material between the three phases at short times. In 298 both blend compositions, the $\mathrm{PMMA}_{1}$-rich $\beta$ phase grows at the expense of the $\mathrm{RCBB}_{1}$-rich $\gamma$

299 phase, consistent with limited miscibility between these constituents. Figure 3 includes a

300 statistical analysis of the PMMA-rich domain size distributions ( $\beta$ phase) as a function of time.

301 Within 30 minutes of annealing, the microstructures are resistant to further coarsening, which

302 demonstrates that the bottlebrush-rich $\gamma$ phase creates a strong encapsulation layer. For

303 comparison, the minority phase in neat blends will coarsen over the same time scales, and these 304 data are summarized in Figure S6. 


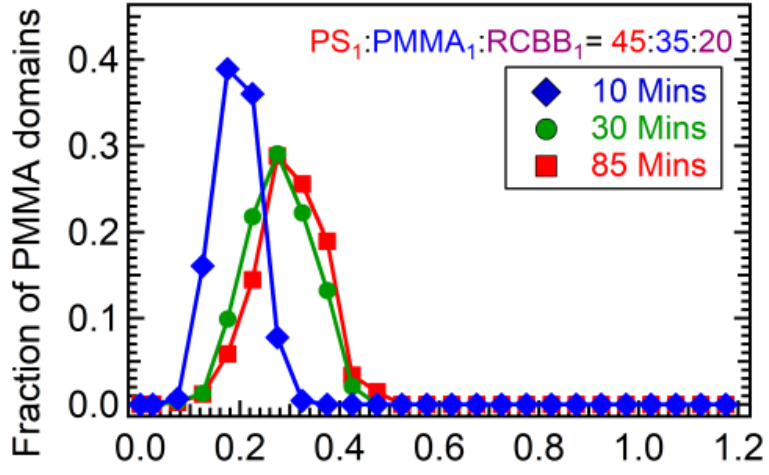

(a) Domain Size $(\mu \mathrm{m})$

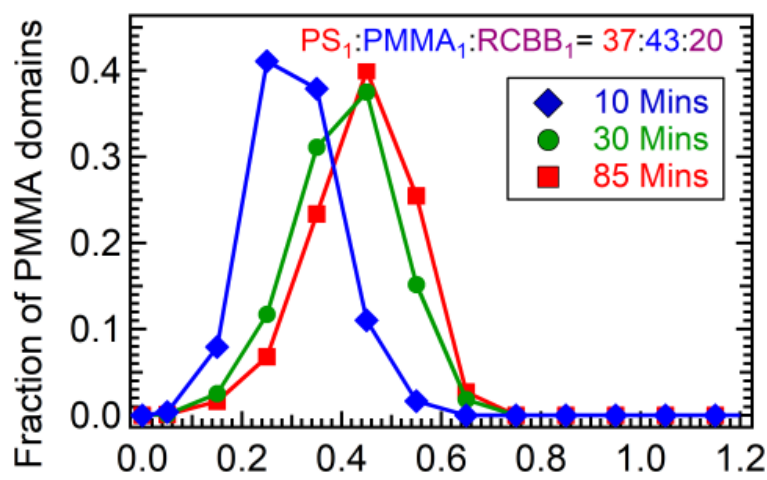

(b) Domain Size $(\mu \mathrm{m})$

Figure 3. Domain size distributions of $\beta$ phase in $\mathrm{PS}_{1} / \mathrm{PMMA}_{1}$ with $20 \mathrm{vol} \%$ of $\mathrm{RCBB}_{1}$ additive. Relative volume of $\mathrm{PS}_{1}: \mathrm{PMMA}_{1}$ blend constituents is fixed at (a) 57:43 and (b) and 47:53.

We also investigated the effects of additive loading by preparing a 57:43 $\mathrm{PS}_{1}: \mathrm{PMMA}_{1}$ blend with 12 vol\% of $\mathrm{RCBB}_{1}$ additive $\left(\mathrm{PS}_{1} / \mathrm{PMMA}_{1} / \mathrm{RCBB}_{1}=49: 39: 12\right)$, and then compared the results with blends that have same proportions of $\mathrm{PS}_{1}: \mathrm{PMMA}_{1}$ but 20 vol\% of $\mathrm{RCBB}_{1}$ additive $\left(\mathrm{PS}_{1} / \mathrm{PMMA}_{1} / \mathrm{RCBB}_{1}=45: 35: 20\right)$. First, we observe a decrease in the average size of the PMMA-rich domains when the RCBB additive loading increases from 12 to $20 \mathrm{vol} \%$.

Second, the PMMA-rich domains coarsen over time with 12 vol\% additive, while the coarsening is suppressed after 30 mins with $20 \mathrm{vol} \%$ additive (Figure 3). These behaviors are attributed to a thicker interphase with higher RCBB loading ${ }^{13,16}$ : as shown in Figure 4a, with 12 vol\% additive, the interfacial layer is not observed in all regions. 

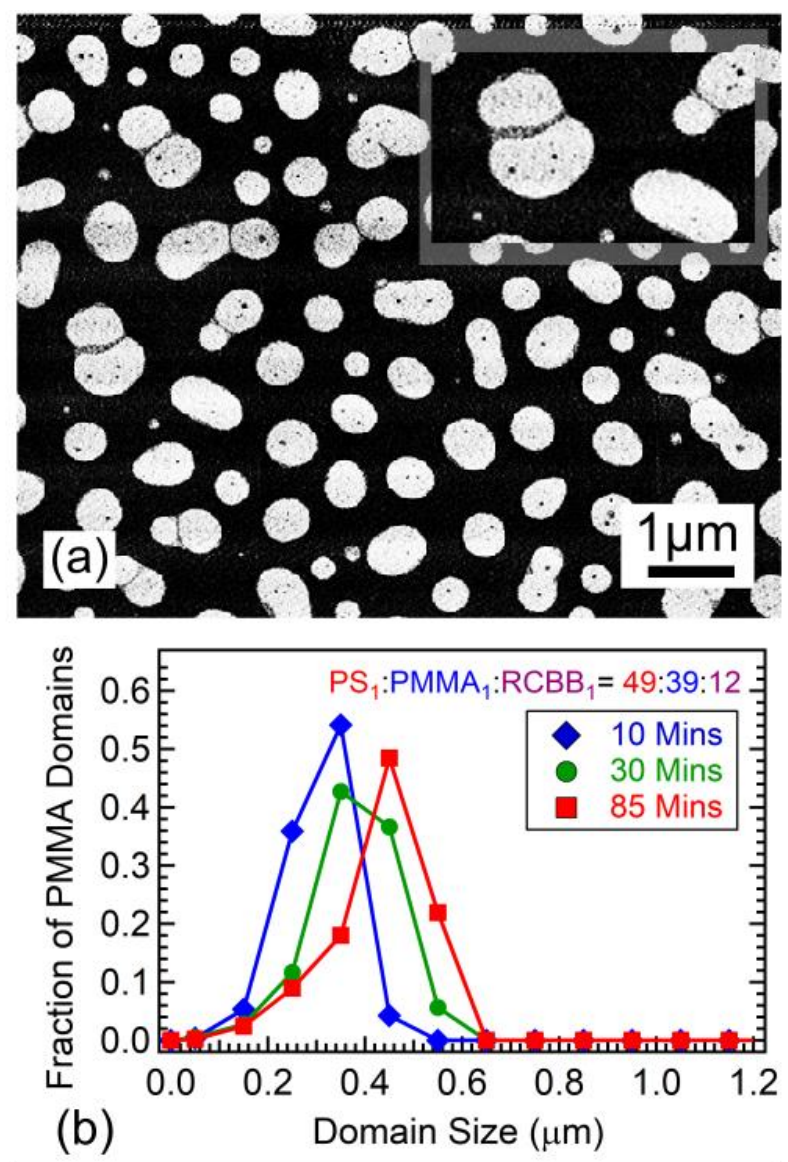

Figure 4: (a) AFM phase image of 57: $43 \mathrm{PS}_{1} / \mathrm{PMMA}_{1}$ blends with 12 vol\% of $\mathrm{RCBB}_{1}$ additive annealed for 85 mins and (b) time evolution of domain size distribution.

As previously discussed, the formation of an encapsulation layer in $\mathrm{PS}_{1} / \mathrm{PMMA}_{1} / \mathrm{RCBB}_{1}$ blends might be attributed to an entropy-controlled de-mixing of $\mathrm{PMMA}_{1}$ and $\mathrm{RCBB}_{1}$. To test this point, we prepared ternary blends using $\mathrm{PS}_{1} / \mathrm{PMMA}_{2} / \mathrm{RCBB}_{1} . \mathrm{PMMA}_{2}$ is a slightly lower molecular weight than $\mathrm{PMMA}_{1}$, and may therefore be a better "solvent" for the RCBB additive. ${ }^{26,27}$ If the $\mathrm{RCBB}_{1}$ additive is evenly partitioned between the two phases, then we expect a transition from a PS-rich to PMMA-rich majority phase near $\Phi$, PS $\approx 0.5$. Ternary blends were prepared with 20 vol\% of $\mathrm{RCBB}_{1}$ additive and $\mathrm{PS}_{1}: \mathrm{PMMA}_{2}$ volume ratios of 57:43, 52:48, and 

time. Figures S8-S9 includes additional AFM and OM data for all blends.
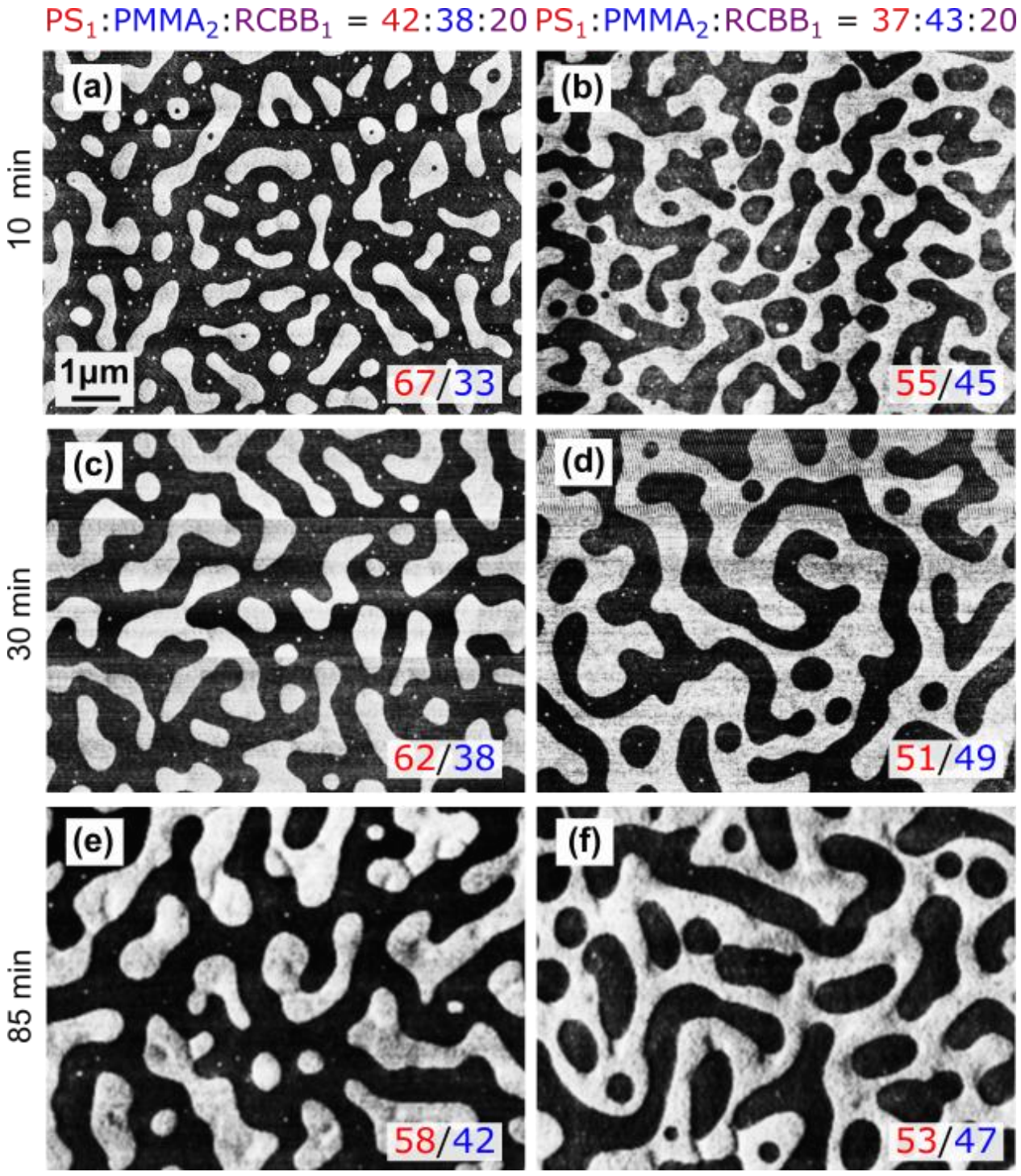

Figure 5. AFM phase images of $\mathrm{PS}_{1} / \mathrm{PMMA}_{2}$ blends with 20 vol\% $\mathrm{RCBB}$ additive. (a,b) $10 \mathrm{~min}$; (c,d) 30 min; and (e,f) 85 min. The $\alpha, \beta$, and $\gamma$ phases are dark, bright, and intermediate contrast, respectively. Relative volume of blend constituents is fixed in each column (left: 52:48, right: 47:53), and relative volumes of $\alpha: \beta$ phases are marked in the bottom-right of each image.

Upon annealing, the $\mathrm{PS}_{1} / \mathrm{PMMA}_{2} / \mathrm{RCBB}$ blends form two phases, PS-rich $(\alpha)$ and PMMA-rich $(\beta)$. Through qualitative inspection and quantitative analysis of the AFM micrographs, we conclude that the $\mathrm{RCBB}_{1}$ additive is soluble in both $\mathrm{PS}_{1}$ and $\mathrm{PMMA}_{2}$ : First, 
342 there is no sign of an encapsulation layer at any annealing time. Second, the structure "inverts"

343 near the expected $\Phi$, PS $\approx 0.5$ for a neat blend: a PS-rich majority phase is observed when the ratio

344 of $\mathrm{PS}_{1}: \mathrm{PMMA}_{2}$ is 57:43 (Figure S8-S9) and 52:48 (Figure 5a,c,e), while a PMMA-rich majority

345 phase is observed for the 47:53 ratio (Figure 5b,d,f). Finally, through image analysis and mass

346 balances, we find that bottlebrush is equally soluble in the $\alpha$ and $\beta$ phases. The calculated

347 composition of each phase after 85 min of annealing is reported in Table 5 . These outcomes

348 support the hypothesis that entropic effects associated with wetting at the bottlebrush/linear

349 interface are partly controlling the miscibility of the bottlebrush and PMMA constituents. The

350 transition from a state of complete to partial miscibility occurs when the linear PMMA chains are

$351 \quad 2.5-3$ times longer than the bottlebrush side chains, which is consistent with a prior study of

352 bottlebrush/linear polystyrene blends, ${ }^{26}$ and similar to predictions for homopolymer/brush

353 wetting at low curvature surfaces. ${ }^{40}$

Table 5: Compositions of PS-rich $(\alpha)$ and PMMA-rich $(\beta)$ phases in PS1/PMMA2:RCBB blends, calculated from analysis of $V^{\alpha}$, $V^{\beta}$, and $V^{\gamma}$ in 45:35:20, 42:38:20, and 37:43:20 blends. $85 \mathrm{~min}$ anneal.

\begin{tabular}{|c|c|c|}
\hline $\mathrm{PX}$ & $\varphi_{P X}^{\alpha}$ & $\varphi_{P X}^{\beta}$ \\
\hline $\mathrm{PS}_{1}$ & 0.7 & $\sim 0$ \\
\hline $\mathrm{PMMA}_{2}$ & 0.1 & 0.8 \\
\hline $\mathrm{RCBB}_{1}$ & 0.2 & 0.2 \\
\hline
\end{tabular}

The microstructure in $\mathrm{PS}_{1} / \mathrm{PMMA}_{2} / \mathrm{RCBB}$ blends is distinct from neat blends or blends with RC additive: small, circular minority domains are aggregated in longer chains, much like the $\mathrm{PS}_{1} / \mathrm{PMMA}_{1} / \mathrm{RCBB}_{1}$ system. This suggests that some $\mathrm{RCBB}_{1}$ additive accumulates at the $\mathrm{PS}_{1} / \mathrm{PMMA}_{2}$ interface during the early stages of annealing, perhaps a monolayer (or less) that cannot be detected with AFM. However, a thin surfactant-like layer cannot stabilize the microstructure against coarsening. Through visual inspection of Figure 4, we see that minority 
364 domains in the blend are growing over the time scale of the experiment, which is confirmed by

365 the complete statistical analysis in Figure 6. Figure 6a reports the size distribution of PMMA-

366 rich domains ( $\beta$ phase) for a blend composition of 52:48 $\mathrm{PS}_{1}: \mathrm{PMMA}_{2}$. Figure $6 \mathrm{~b}$ reports the size

367 distribution of PS-rich domains ( $\alpha$ phase) for a blend composition of 47:53 $\mathrm{PS}_{1}: \mathrm{PMMA}_{2}$, as the

368 PMMA-rich domains form a continuous matrix.
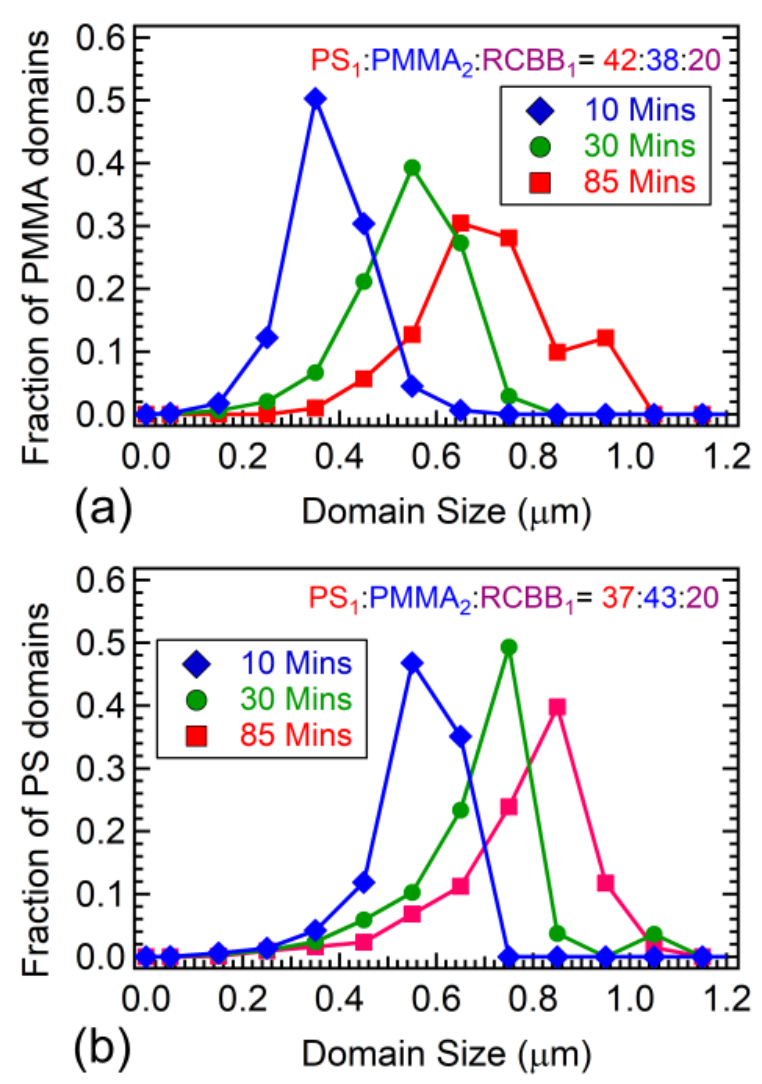

Figure 6. Domain size distributions of $\mathrm{PS}_{1} / \mathrm{PMMA}_{2}$ with 20 vol\% of RCBB additive. Relative volume of $\mathrm{PS}_{1} / \mathrm{PMMA}_{2}$ blend constituents is fixed at (a) 52:48 and (b) 47:53

To further illustrate the formation and function of RCBB encapsulation layers, we prepared ternary blends of $\mathrm{PS}_{2} / \mathrm{PMMA}_{3} / \mathrm{RCBB}_{1}$. Both $\mathrm{PS}_{2}$ and $\mathrm{PMMA}_{3}$ have higher molecular weights than all other PS and PMMA blend constituents $\left(\mathrm{PS}_{1}, \mathrm{PMMA}_{1}, \mathrm{PMMA}_{2}\right)$. As with the other blends, if the bottlebrush is evenly partitioned between the two homopolymers, then we anticipate a transition from PS-rich to PMMA-rich majority phase when $\Phi_{\mathrm{PS}} \approx 0.5$. Ternary 
381 different regions, as shown in Figure S11.
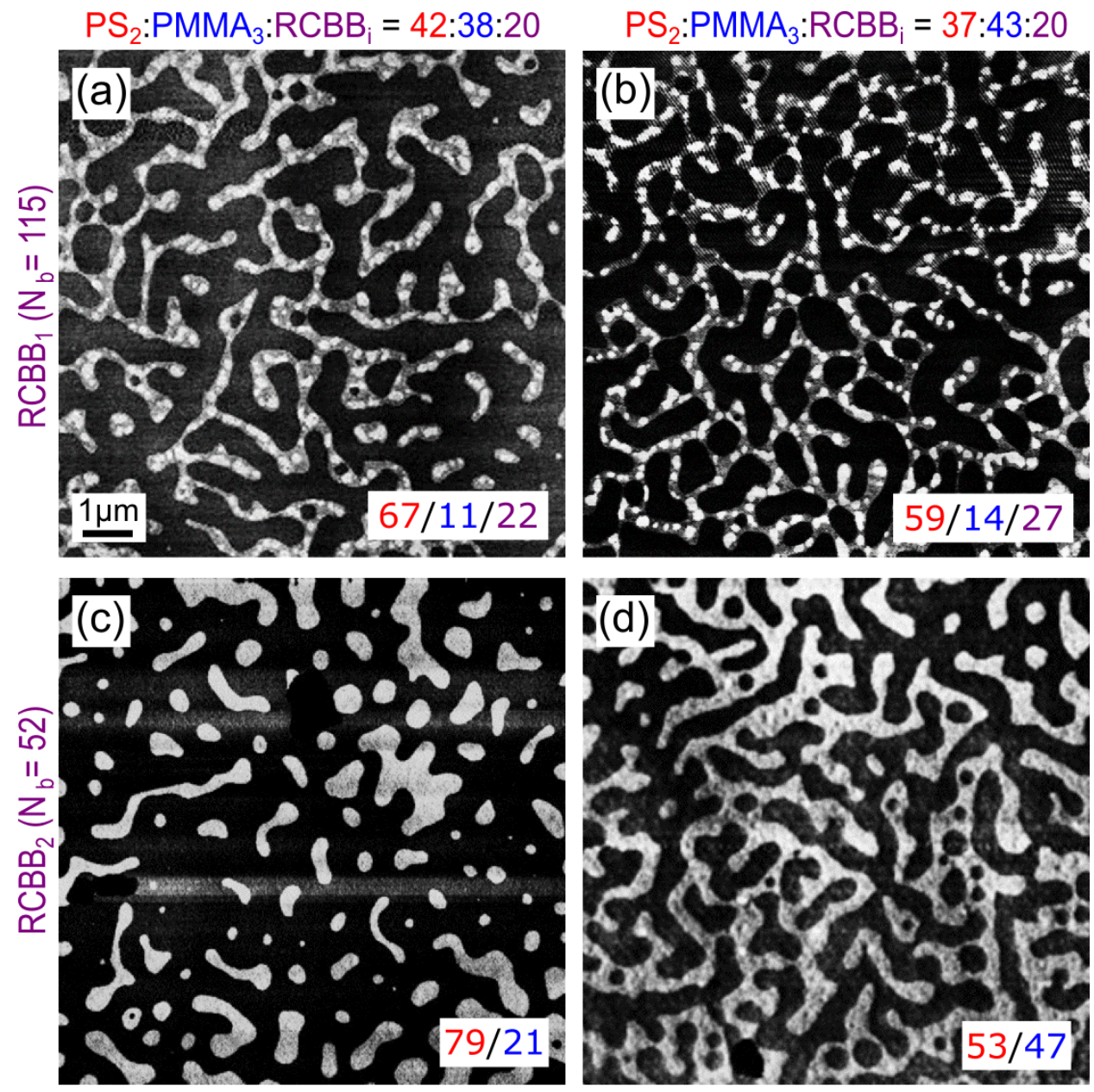

Figure 7: AFM phase images of $\mathrm{PS}_{2} / \mathrm{PMMA}_{3}$ blends with 20 vol\% of RCBB additives of different backbone lengths and annealed for $85 \mathrm{~min}$. The proportion of $\mathrm{PS}_{2} / \mathrm{PMMA}_{3}$ in blends are (a, c) 52:48 and (b, d) 47:53. The backbone length of the RCBB additives is fixed in each row (top: $\mathrm{N}_{b}=115$, bottom: $\mathrm{N}_{\mathrm{b}}=52$ ), Relative volumes of the blend constituents are noted in on the left side of the micrograph, and the relative volumes of $\alpha: \beta$ or $\alpha: \beta: \gamma$ phases are marked in the bottom-right of each image. The contrast of $\alpha, \beta$, and $\gamma$ phases are dark, bright, and intermediate, respectively.

From the AFM images, we observe a three-phase system, i.e. a PS-rich $\alpha$ phase, a PMMA-rich $\beta$ phase and a RCBB-rich $\gamma$ phase. Based on the previous analysis of the PS/PMMA 
systems, we expect the $\mathrm{RCBB}_{1}$ additive to have very limited miscibility in the higher molecular

394 weight PMMA phase ( $\beta$ phase), but it is unclear if increasing the length of the PS chains will

395 reduce bottlebrush/PS miscibility. We do not apply mass balances to this blend system, as the

396 domain sizes are not uniform throughout the film thickness: the widths of the PMMA/RCBB

397 features increase with depth into the film, a sign of preferential wetting by PS at the free surface

398 and/or PMMA at the substrate (Figure S4-S5). However, we offer a few qualitative observations

399 based on the area fraction of each phase at the surface: First, as in the other blends, a PS-majority

400 phase is observed when $\Phi_{\mathrm{PS}}<0.5$, which suggests that $\mathrm{RCBB}_{1}$ remains soluble in $\mathrm{PS}$ as

401 molecular weights are increased. Second, the interphase is considerably more diffuse, and its

402 area fraction (at the surface) exceeds the volume fraction of $\mathrm{RCBB}_{1}$ in the blend. This may

403 reflect a greater surface attraction for the branched additive compared with a long linear

404 polymer. ${ }^{26,41,42}$ Finally, we note that the interphase is continuous throughout the plane of the film

405 in Figure $7 \mathrm{~b}\left(\mathrm{PS}_{2}: \mathrm{PMMA}_{3}=47: 53\right)$, despite the relatively low concentration of $\mathrm{RCBB}_{1}$ in the

406 blend. Furthermore, the interphase is nearly continuous in the $\mathrm{PS}_{1} / \mathrm{PMMA}_{1} / \mathrm{RCBB}_{1}$ blends and

$407 \mathrm{PS}_{2} / \mathrm{PMMA}_{3} / \mathrm{RCBB}_{1}$ blends shown in Figure $2 \mathrm{~b}$ and Figure $7 \mathrm{a}$, respectively, where the

408 proportion of PS in the blend is slightly higher $\left(\mathrm{PS}_{2}: \mathrm{PMMA}_{3}=52: 48\right)$. Continuous minority

409 phases are notoriously difficult to achieve in blend systems ${ }^{43}$, but have been observed in other

410 studies that employ architecturally-complex compatibilizers ${ }^{44}$, albeit with different underlying

411 thermodynamics.

Analysis of the domain sizes in the $\mathrm{PS}_{2} / \mathrm{PMMA}_{3} / \mathrm{RCBB}_{1}$ blends confirms that the

413 encapsulation layer suppresses coalescence of the PMMA-rich domains after 30 mins of

414 annealing. The time evolution of domain sizes is reported in Figure 8 for blends with

$415 \mathrm{PS}_{2} / \mathrm{PMMA}_{3}=57: 43$ (Figure 8a) and 47:53 (Figure 8b). Note that Figure 8a illustrates the size 
416 distribution of the encapsulated PMMA domains, while Figure $8 \mathrm{~b}$ reports the size distribution of

417 the PS domains. In Figure 8a, we report the size distribution of PMMA domains with the

418 interphase encapsulation layer because it was difficult to identify the individual PMMA domains.

419 In Figure 8b, we report the size distribution of PS domains because the encapsulated PMMA

420 domains formed a continuous matrix.

421

422

423

424

425

426
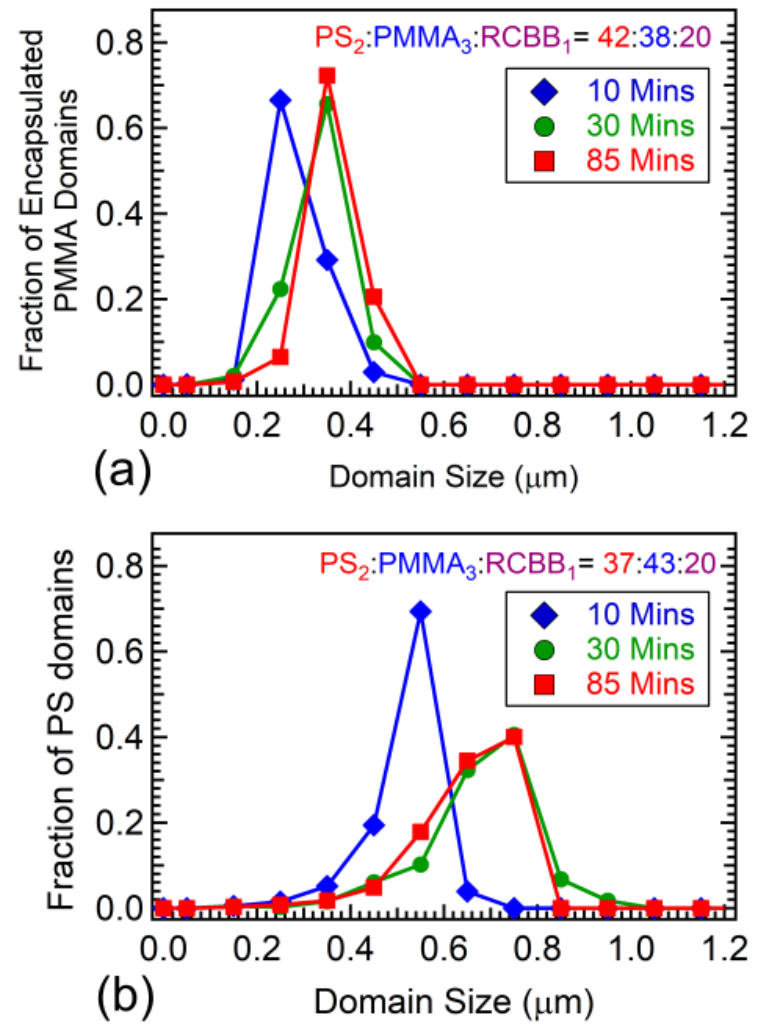

Figure 8: Domain size distributions of $\mathrm{PS}_{2} / \mathrm{PMMA}_{3}$ with $20 \mathrm{vol} \%$ of $\mathrm{RCBB}_{1}$ additive. Relative volume of $\mathrm{PS}_{2} / \mathrm{PMMA}_{3}$ blend constituents is fixed at (a) 57:43 and (b) 47:53.

We also studied the effects of the bottlebrush backbone length, $N_{b}$, by preparing ternary blends using $\mathrm{PS}_{2}$ and $\mathrm{PMMA}_{3}$ homopolymers with $\mathrm{RCBB}_{2}$ at volume ratios of 57:43, 52:48, and 47:53. $\mathrm{RCBB}_{2}$ is a random copolymer bottlebrush additive with the same side chain length and 
430 styrene composition as $\mathrm{RCBB}_{1}$, but with a shorter backbone length, i.e., $\mathrm{N}_{\mathrm{b}}=52$ instead of $\mathrm{N}_{\mathrm{b}}=$

431 115. The different backbone length changes the overall size of the additive as well as the aspect

432 ratio. We then compared this system to the same blend compositions with $20 \mathrm{vol} \% \mathrm{RCBB}_{1}$.

433 Outcomes are reported in Figure 7. Additional AFM images and OM images for this study are 434 included in Supporting Information.

From the AFM results, we observe a transition from a three-phase system to a two-phase 436 system for all $\mathrm{PS}_{2} / \mathrm{PMMA}_{3}$ blend compositions as the backbone length of the RCBB additive

437 decreases. Considering that the volume of the PMMA-rich phase increases as backbone length is 438 reduced, we conclude that miscibility with PMMA is enhanced by this change to the bottlebrush 439 architecture. As the chemistry of the bottlebrush is unchanged, this enhancement is due to a gain 440 in the configurational entropy of mixing. In the context of a Flory-type model for architecturally441 complex blends, the bottlebrush is viewed as a linear polymer with degree of polymerization $\mathrm{N}_{\mathrm{b}}$ 442 and monomer size

\section{CONCLUSIONS}

We examined the effects of bottlebrush P(S-r-MMA) additives on the phase behavior of

446 PS/PMMA polymer blends in thin films. The bottlebrush side chain length and composition are

447 fixed at $N \mathrm{sc}=59$ and $61 \mathrm{~mol} \%$ styrene, respectively, and the bottlebrush concentration in the

448 blends is $20 \mathrm{vol} \%$. We demonstrate that subtle changes in bottlebrush architecture and

449 homopolymer chain lengths can have a large impact on phase behavior, domain coarsening, and

450 domain continuity. The bottlebrush copolymer additives are miscible with PS under all the

451 conditions we studied, which is contrary to prior studies with linear copolymer architectures (60 
452 mol\% styrene) that report greater miscibility with PMMA. ${ }^{39}$ This discrepancy might be a 453 consequence of the dodecyl-terminated chain ends at the bottlebrush/PS interface, but further 454 studies with different end groups are needed to clarify such effects. In contrast, bottlebrush 455 miscibility with PMMA is a function of the overall bottlebrush size and the relative length of 456 PMMA chains to bottlebrush side chains. When the bottlebrush backbone is short $\left(\mathrm{N}_{\mathrm{b}}=52\right)$, 457 and/or the PMMA homopolymer chain lengths are short $(\mathrm{N}=133)$, the bottlebrush additives are 458 equally miscible with both PS and PMMA. Therefore, the phase separation process is largely 459 controlled by immiscibility between PS and PMMA, and the resulting structure is comprised of 460 PS-rich and PMMA-rich domains that coarsen with time. However, by increasing the length of 461 the bottlebrush backbone (115 branches) and the PMMA homopolymer ( $N \geq 146)$, the 462 bottlebrush/PMMA miscibility is reduced. As a result, the system separates into three-phases: 463 PS-rich, PMMA-rich, and a bottlebrush-rich interphase. We suggest that bottlebrush/PMMA 464 miscibility is largely controlled by 1) conformational entropy of side chains, which is tied to 465 wetting at the brush/linear interface; and 2) the configurational entropy of mixing, which is 466 controlled by the overall sizes of bottlebrushes and linear polymers. Significantly, under 467 conditions that produce three phases, the bottlebrush-rich interphase encapsulates the PMMA468 rich domains and suppresses their coarsening at elevated temperatures. Furthermore, the 469 encapsulated PMMA-rich domains are aggregated into longer strings, and the blend composition 470 can be tuned to produce continuity in this microstructure. Bottlebrush additives offer a few 471 unique attributes that could be useful for fundamental studies of soft, brushy nanoparticles, as 472 well as select applications: they are entirely organic, their aspect ratio and composition is easily 473 tuned through synthesis, and they do not entangle during processing. 


\section{ASSOCIATED CONTENT}

476 Supporting Information.

477 Additional studies involving a bottlebrush copolymer with a mixture of PS and PMMA side

478 chains, additional studies with random copolymer side chains having different styrene

479 compositions, additional studies with mixed side chains, and details that pertain to image

480 analysis and mass balances. This material is available free of charge via the Internet at

481 http://pubs.acs.org.

482

483 AUTHOR INFORMATION

484 Corresponding Author

485 * gstein4@utk.edu; rafaelv@rice.edu

\section{Author Contributions}

487 The manuscript was written through contributions of all authors. All authors have given approval

488 to the final version of the manuscript.

489 Notes

490 The authors declare no competing financial interests.

\section{ACKNOWLEDGMENT}

492 H.Z. Mah and G.E. Stein acknowledge financial support from the National Science Foundation 493 under Grant No. DMR-1 151468 and CMMI- 1740457. P. Afzali acknowledges financial support 494 from the UH SURF and PURS programs, and an REU supplement from the National Science 495 Foundation under Grant No. DMR-1151468. L. Qi, S.L. Pesek, and R. Verduzco acknowledge 496 financial support from the National Science Foundation under Grant No. CMMI-1563008 and 497 the Welch Foundation for Chemical Research under Grant No. C-1888.

\section{REFERENCES}


501 (1) Robeson, L. Historical Perspective of Advances in the Science and Technology of Polymer

502 Blends. Polymers 2014, 6 (5), 1251-1265.

503 (2) Robeson, L. M. Polymer Blends: A Comprehensive Review; Hanser: Munich, 2007.

504 (3) Eitouni, H. B.; Balsara, N. P. Thermodynamics of Polymer Blends. In Physical Properties of 505 Polymers Handbook; Mark, J. E., Ed.; Springer New York, 2007; pp 339-356.

506 (4) Fredrickson, G. H.; Bates, F. S. Design of Bicontinuous Polymeric Microemulsions. J. Polym. 507 Sci. Part B Polym. Phys. 1997, 35 (17), 2775-2786.

508 (5) Anderson, K. S.; Hillmyer, M. A. The Influence of Block Copolymer Microstructure on the 509 Toughness of Compatibilized Polylactide/Polyethylene Blends. Polymer 2004, 45 (26), 8809-8823.

510 (6) Galloway, J. A.; Jeon, H. K.; Bell, J. R.; Macosko, C. W. Block Copolymer Compatibilization of 511 Cocontinuous Polymer Blends. Polymer 2005, 46 (1), 183-191.

512 (7) Lyatskaya, Y.; Gersappe, D.; Balazs, A. C. Effect of Copolymer Architecture on the Efficiency of 513 Compatibilizers. Macromolecules 1995, 28 (18), 6278-6283.

514 (8) Lyatskaya, Y.; Gersappe, D.; Gross, N. A.; Balazs, A. C. Designing Compatibilizers To Reduce 515 Interfacial Tension in Polymer Blends. J. Phys. Chem. 1996, 100 (5), 1449-1458.

516 (9) Shull, K. R.; Kellock, A. J.; Deline, V. R.; MacDonald, S. A. Vanishing Interfacial Tension in an 517 Immiscible Polymer Blend. J. Chem. Phys. 1992, 97 (3), 2095-2104.

$518 \quad$ (10) Lefebvre, M. D.; Dettmer, C. M.; McSwain, R. L.; Xu, C.; Davila, J. R.; Composto, R. J.; 519 Nguyen, S. T.; Shull, K. R. Effect of Sequence Distribution on Copolymer Interfacial Activity. 520 Macromolecules 2005, 38 (25), 10494-10502.

521 (11) Eastwood, E. A.; Dadmun, M. D. Multiblock Copolymers in the Compatibilization of Polystyrene 522 and Poly(Methyl Methacrylate) Blends: Role of Polymer Architecture. Macromolecules 2002, 35 (13), $5235069-5077$.

524 (12) Ku, K. H.; Yang, H.; Jang, S. G.; Bang, J.; Kim, B. J. Tailoring Block Copolymer and Polymer 525 Blend Morphology Using Nanoparticle Surfactants. J. Polym. Sci. Part Polym. Chem. 2015, n/a-n/a.

526 (13) Bryson, K. C.; Löbling, T. I.; Müller, A. H. E.; Russell, T. P.; Hayward, R. C. Using Janus 527 Nanoparticles To Trap Polymer Blend Morphologies during Solvent-Evaporation-Induced Demixing. 528 Macromolecules 2015.

529 (14) Fenouillot, F.; Cassagnau, P.; Majesté, J.-C. Uneven Distribution of Nanoparticles in Immiscible 530 Fluids: Morphology Development in Polymer Blends. Polymer 2009, 50 (6), 1333-1350.

531 (15) Chung, H.; Ohno, K.; Fukuda, T.; Composto, R. J. Self-Regulated Structures in Nanocomposites 532 by Directed Nanoparticle Assembly. Nano Lett. 2005, 5 (10), 1878-1882.

533 (16) Walther, A.; Matussek, K.; Müller, A. H. E. Engineering Nanostructured Polymer Blends with 534 Controlled Nanoparticle Location Using Janus Particles. ACS Nano 2008, 2 (6), 1167-1178.

535 (17) Ruzette, A.-V.; Leibler, L. Block Copolymers in Tomorrow's Plastics. Nat. Mater. 2005, 4 (1), $536 \quad 19-31$. 
(18) Kulasekere, R.; Kaiser, H.; Ankner, J. F.; Russell, T. P.; Brown, H. R.; Hawker, C. J.; Mayes, A. M. Homopolymer Interfaces Reinforced with Random Copolymers. Macromolecules 1996, 29 (16), 5493-5496.

(19) Pieranski, P. Two-Dimensional Interfacial Colloidal Crystals. Phys. Rev. Lett. 1980, 45 (7), 569572.

(20) Kim, S.; Yoo, M.; Kang, N.; Moon, B.; Kim, B. J.; Choi, S.-H.; Kim, J. U.; Bang, J. Nanoporous Bicontinuous Structures via Addition of Thermally-Stable Amphiphilic Nanoparticles within Block Copolymer Templates. ACS Appl. Mater. Interfaces 2013, 5 (12), 5659-5666.

(21) Yoo, M.; Kim, S.; Lim, J.; Kramer, E. J.; Hawker, C. J.; Kim, B. J.; Bang, J. Facile Synthesis of Thermally Stable Core-Shell Gold Nanoparticles via Photo-Cross-Linkable Polymeric Ligands. Macromolecules 2010, 43 (7), 3570-3575.

(22) Verduzco, R.; Li, X.; Pesek, S. L.; Stein, G. E. Structure, Function, Self-Assembly, and Applications of Bottlebrush Copolymers. Chem. Soc. Rev. 2015, 44 (8), 2405-2420.

(23) Paturej, J.; Sheiko, S. S.; Panyukov, S.; Rubinstein, M. Molecular Structure of Bottlebrush Polymers in Melts. Sci. Adv. 2016, 2 (11), e1601478.

(24) Sheiko, S. S.; Zhou, J.; Arnold, J.; Neugebauer, D.; Matyjaszewski, K.; Tsitsilianis, C.; Tsukruk, V. V.; Carrillo, J.-M. Y.; Dobrynin, A. V.; Rubinstein, M. Perfect Mixing of Immiscible Macromolecules at Fluid Interfaces. Nat. Mater. 2013, 12 (8), 735-740.

(25) Pesek, S. L.; Lin, Y.-H.; Mah, H. Z.; Kasper, W.; Chen, B.; Rohde, B. J.; Robertson, M. L.; Stein, G. E.; Verduzco, R. Synthesis of Bottlebrush Copolymers Based on Poly(Dimethylsiloxane) for Surface Active Additives. Polymer.

(26) Mitra, I.; Li, X.; Pesek, S. L.; Makarenko, B.; Lokitz, B. S.; Uhrig, D.; Ankner, J. F.; Verduzco, R.; Stein, G. E. Thin Film Phase Behavior of Bottlebrush/Linear Polymer Blends. Macromolecules 2014, 47 (15), 5269-5276.

(27) Sun, F. C.; Dobrynin, A. V.; Shirvanyants, D.; Lee, H.-I.; Matyjaszewski, K.; Rubinstein, G. J.; Rubinstein, M.; Sheiko, S. S. Flory Theorem for Structurally Asymmetric Mixtures. Phys. Rev. Lett. 2007, 99 (13), 137801.

(28) Wang, H. S.; Khan, A.; Choe, Y.; Huh, J.; Bang, J. Architectural Effects of Organic Nanoparticles on Block Copolymer Orientation. Macromolecules 2017, 50 (13), 5025-5032.

(29) Sanford, M. S.; Love, J. A.; Grubbs, R. H. A Versatile Precursor for the Synthesis of New Ruthenium Olefin Metathesis Catalysts. Organometallics 2001, 20 (25), 5314-5318.

(30) Mansky, P.; Liu, Y.; Huang, E.; Russell, T. P.; Hawker, C. Controlling Polymer-Surface Interactions with Random Copolymer Brushes. Science 1997, 275 (5305), 1458-1460.

(31) Ahn, D. U.; Wang, Z.; Campbell, I. P.; Stoykovich, M. P.; Ding, Y. Morphological Evolution of Thin PS/PMMA Films: Effects of Surface Energy and Blend Composition. Polymer 2012, 53 (19), 41874194.

(32) Mahadevapuram, N.; Mitra, I.; Bozhchenko, A.; Strzalka, J.; Stein, G. E. In-Plane and out-ofPlane Defectivity in Thin Films of Lamellar Block Copolymers. J. Polym. Sci. Part B Polym. Phys. 2016, 54 (2), 339-352. 
$576 \quad$ (33) Heriot, S. Y.; Jones, R. A. L. An Interfacial Instability in a Transient Wetting Layer Leads to 577 Lateral Phase Separation in Thin Spin-Cast Polymer-Blend Films. Nat. Mater. 2005, 4 (10), $782-786$.

578 (34) Wu, S. Polar and Nonpolar Interactions in Adhesion. J. Adhes. 1973, 5 (1), 39-55.

579 (35) Walheim, S.; Böltau, M.; Mlynek, J.; Krausch, G.; Steiner, U. Structure Formation via Polymer 580 Demixing in Spin-Cast Films. Macromolecules 1997, 30 (17), 4995-5003.

581 (36) Rubinstein, R. H., Michael, Colby. Polymer Physics; Oxford University Press, 2003.

582 (37) Li, X.; ShamsiJazeyi, H.; Pesek, S. L.; Agrawal, A.; Hammouda, B.; Verduzco, R.

583 Thermoresponsive PNIPAAM Bottlebrush Polymers with Tailored Side-Chain Length and End-Group

584 Structure. Soft Matter 2014, 10 (12), 2008.

$585 \quad$ (38) Kohl, P. R.; Seifert, A. M.; Hellmann, G. P. Miscibility of Poly (Styrene-Co-

586 Methylmethacrylate)s Differing in Composition. J. Polym. Sci. Part B Polym. Phys. 1990, 28 (8), 13095871326.

588 (39) Kulasekere, R.; Kaiser, H.; Ankner, J. F.; Russell, T. P.; Brown, H. R.; Hawker, C. J.; Mayes, A. 589 M. Homopolymer Interfaces Reinforced with Random Copolymers. Macromolecules 1996, 29 (16), $590 \quad 5493-5496$.

591 (40) Trombly, D. M.; Ganesan, V. Curvature Effects upon Interactions of Polymer-Grafted 592 Nanoparticles in Chemically Identical Polymer Matrices. J. Chem. Phys. 2010, 133 (15), 154904.

593 (41) Wu, D. T.; Fredrickson, G. H. Effect of Architecture in the Surface Segregation of Polymer 594 Blends. Macromolecules 1996, 29 (24), 7919-7930.

595 (42) Walton, D. G.; Mayes, A. M. Entropically Driven Segregation in Blends of Branched and Linear 596 Polymers. Phys. Rev. E 1996, 54 (3), 2811-2815.

597 (43) Mezzenga, R.; Ruokolainen, J.; Fredrickson, G. H.; Kramer, E. J.; Moses, D.; Heeger, A. J.; 598 Ikkala, O. Templating Organic Semiconductors via Self-Assembly of Polymer Colloids. Science 2003, $599299(5614), 1872-1874$.

600 (44) Shi, W.; Hamilton, A. L.; Delaney, K. T.; Fredrickson, G. H.; Kramer, E. J.; Ntaras, C.; 601 Avgeropoulos, A.; Lynd, N. A.; Demassieux, Q.; Creton, C. Aperiodic "Bricks and Mortar" Mesophase: 602 A New Equilibrium State of Soft Matter and Application as a Stiff Thermoplastic Elastomer.

603 Macromolecules 2015, 48 (15), 5378-5384.

604 
606

607

608
Table of Contents Graphic

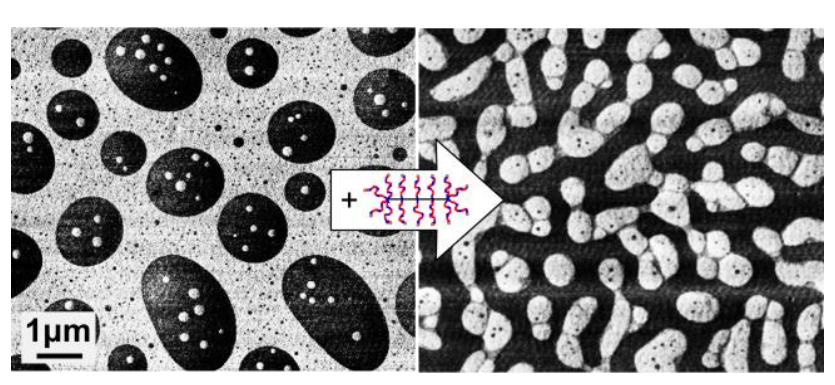

